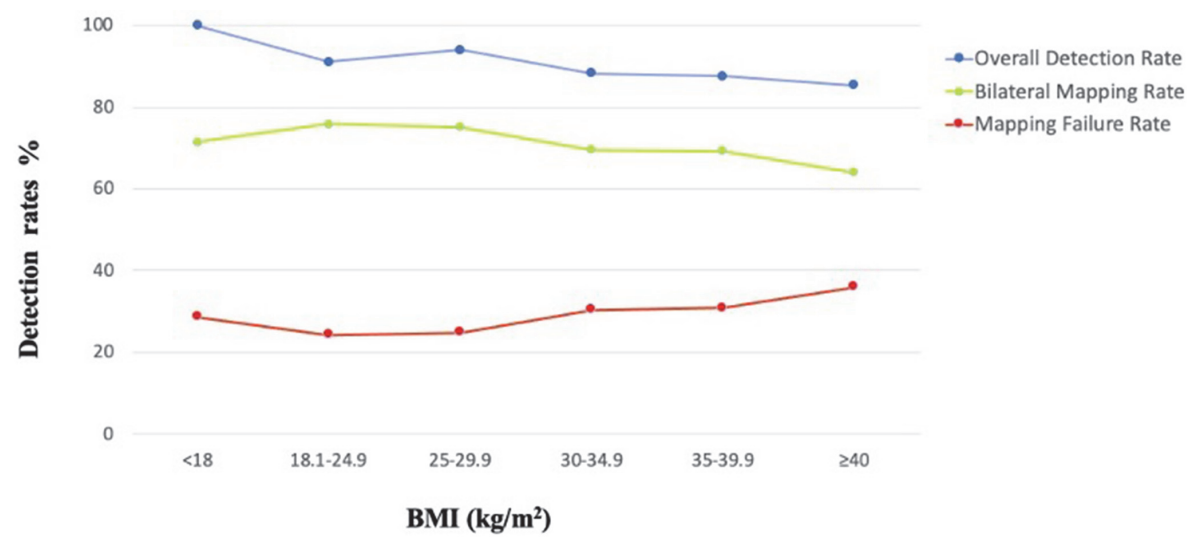

Overall detection rate: $\mathrm{OR} 0.785,95 \% \mathrm{CI} 0.670-0.920, \mathrm{p}=0.003$

Successful bilateral mapping: OR $0.865,95 \%$ CI $0.773-0.968, p=0.012$

Mapping failure risk: OR 1.156, 95\% CI 1.033-1.294, $\mathrm{p}=0.012$

Abstract 806 Figure 1 SLN detection rates per 5-unit of BMI increase and bionominal logistic regresion analysis in the propensity matched population

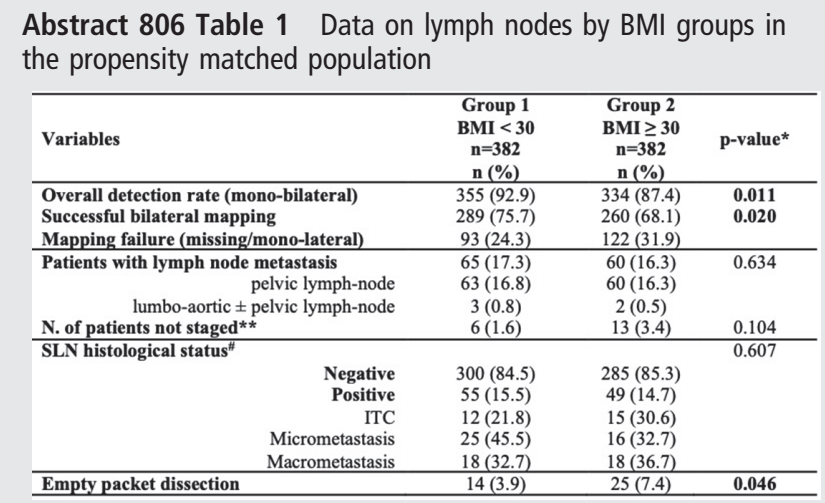

(respectively OR $0.865,95 \%$ CI $0.773-0.968, \mathrm{p}=0.012$ and OR 0.785 , 95\% CI $0.670-0.920, \mathrm{p}=0.003$ ) (figure 1). Furthermore, in the group of obese patients, in 25 cases $(7.4 \%)$ the SLN dissection did not lead to the identification of lymphnode tissue at final histopathological examination ('empty packet dissection') (Group1 vs Group 2: $3.9 \%$ vs $7.4 \%$, $\mathrm{p}=0.046$ ) (table 1).

Conclusion* Controlling for the variables that have been proved to negatively influence the SLN detection rate, BMI was confirmed as a statistically relevant predictor of mapping failure. In addition, obese women had a significantly higher odds of empty packet dissection, which could lead to an unintended surgical understaging.

\section{FERTILITY PRESERVATION IN ENDOMETRIAL CANCER: PERINATAL AND ONCOLOGIC OUTCOMES}

V García Pineda*, M Turiel, M Gracia, I Zapardiel, MD Diestro, J Siegrist, Y Pérez Martínez, A Hernández. La Paz University Hospital, Gynaecological Oncology, Madrid, Spain

\subsection{6/ijgc-2021-ESGO.200}

Introduction/Background* The aim of our study is to evaluate the oncological and perinatal outcomes in young women diagnosed with atypical endometrial hyperplasia (AEH) or endometrial cancer (EC) treated with hormone therapy.
Methodology A single institutional ambispective study was performed including all patients diagnosed with $\mathrm{AEH}$ or $\mathrm{EC}$ grade 1 without myometrial invasion who received hormone therapy between January 2011 and July 2021. We analyzed the complete response rate and recurrence rate of disease and pregnancy rate in these patients as well as perinatal results (live births rate, type of delivery and perinatal morbidity). In addition, we evaluated complete response rate according to type of hormone therapy, dosage received and treatment length.

A review of literature was performed to identify studies involving patients with $\mathrm{AEH}$ or $\mathrm{EC}$ who received fertility sparing management.

All statistical analysis were performed using the software SPSS Statistics v.24.0 (IBM Corp., Armonk, NY, USA).

Result(s)* The results after final statistical analysis will be available when we complete the collection of follow-up data for conservatively treated patients.

Conclusion* Conservative management with progestins of young patients with AEH or EC grade 1 limited to the endometrium is an acceptable possibility given the high remission rate and live birth rates achieved. However, definitive surgical treatment cannot be avoided given the high recurrence rate described in the literature.

\section{A RARE SITUATION: HERNIATION OF BOWEL THROUGH 5 MM TROCAR SITE IN A PATIENT WITH ENDOMETRIAL CARCINOMA}

NA Vural ${ }^{*}$, F Vaizoğlu, S Soylu, B Erdem, N Çetinkaya Kocadal. Başakşehir Çam ve Sakura Şehir Hastanesi, Turkey

\subsection{6/ijgc-2021-ESGO.201}

Introduction/Background* Hernia formation through $5 \mathrm{~mm}$-trocar-site has incidence between $1-6 \%$ in the literature. Practically fascial defect at the 10 -mm-trocar site is closed, while suturing at the 5 -mm-trocar site is not preferred. Because of its rarity, a possible hernia can be underestimated by the clinician and severe intestinal damage may occure as complication of minimally invasive surgery. Here we present a case -who had been operated via laparoscopy due to endometrial 
carcinoma-with bowel strangulation at $5 \mathrm{~mm}$-trocar site in the $4^{\text {th }}$ postoperative day.

\section{Methodology}

CASE PRESENTATION A 69-years old patient had referred to our hospital with the diagnosis of endometrial carcinoma. Minimal invasive staging approach with laparoscopic hysterectomy, bilateral salpingooferectomy and pelvic\&para-aorticlymph-node-dissection was performed. A 10-mm-trocar at the umblical site was inserted with direct technique, and bilateral accessory trocars of $5-\mathrm{mm}$ (two left, one right) were placed under direct visualization. Second 10-mm-trocar positioned as suprapubically was also entered to abdomen for performing para-aortic lymph node dissection. After the operation abdominal drain was introduced from left inferior $5 \mathrm{~mm}$ trocar site. Fascial defect in umblical and suprapubic trocar sites were sutured via vicryl suturing and skin insicions were closed. Patient had no abnormal symptoms throughout early postoperative period. Spontaneous flatus passage was occured in the $2^{\text {nd }}$ postoperative day. On the $4^{\text {th }}$ postoperative day she had non-severe discomforting symptoms as a subtle abdominal pain and nausea. A palpable, $8 \mathrm{~cm}$, subdermal mass was diagnosed on abdominal examination and abdominal computerizedtomography was performed for a suspected early postoperative incisional hematoma or hernia. Bowel-herniation was diagnosed on CT-imaging (figure 1) and exploratory laparotomy was performed for GIS pathology. During operation midline abdominal incision was made and $30 \mathrm{~cm}$ herniated small bowel herniation without strangulation was diagnosed at the left superior $5 \mathrm{~mm}$-trocar-site. No segmental-bowel-resection was performed

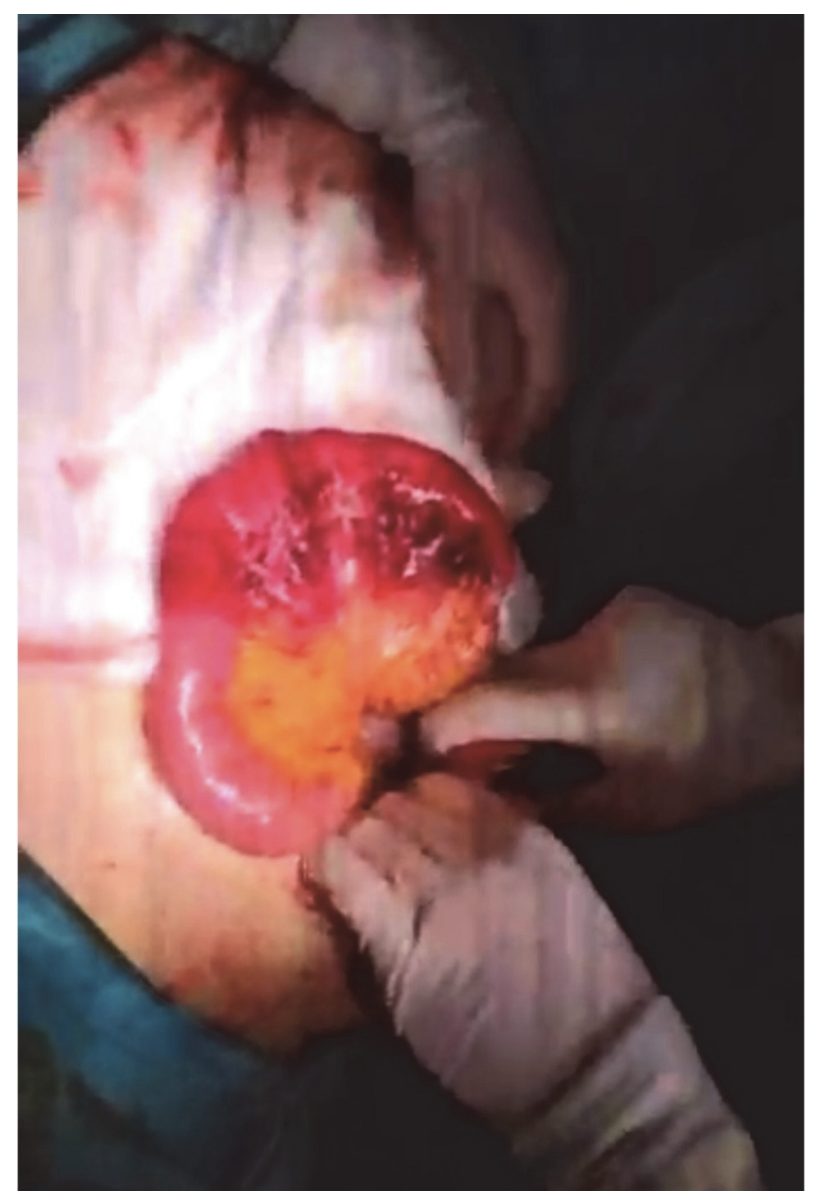

Abstract 828 Figure 1

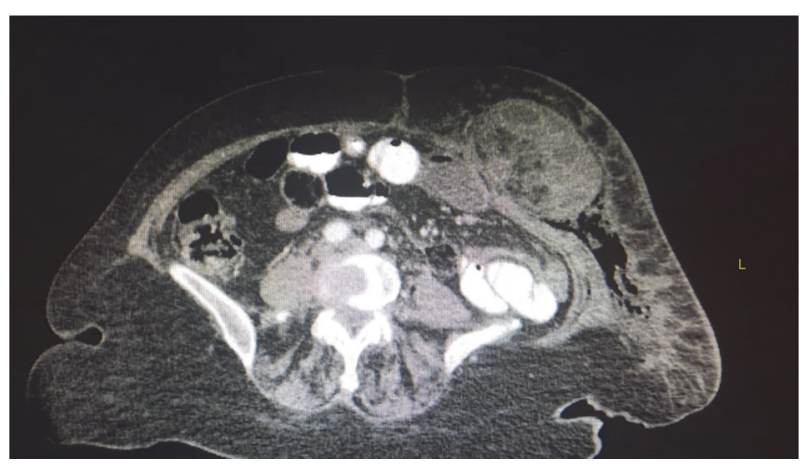

Abstract 828 Figure 2

upon surgery because bowel-segment vascularity and peristaltism were evaluated as well preserved during exploration.

Result(s)* Patient was followed up clinically by physical examination, abdominal drainage and leucocyte and C-reactive-protein levels. On the $7^{\text {th }}$ day after secondary surgery patient was discharge without any further complication.

Conclusion* Early detection of trochar-site-hernia is important because of leading severe morbidity, such as intestinal strangulation and necrosis. After laparoscopic surgery, in the case of unexplained intestinal obstuction and abdominal pain, abdominal-CT imaging is very helpful in diagnosis.

\section{IMPLEMENTATION OF THE 2021 MOLECULAR ESGO/ ESTRO/ESP RISK GROUPS IN ENDOMETRIAL CANCER}

${ }^{1} \mathrm{~S}$ Imboden*, ${ }^{2} \mathrm{D}$ Nastic, ${ }^{2} \mathrm{M}$ Ghaderi, ${ }^{1} \mathrm{~F}$ Siegenthaler, ${ }^{1} \mathrm{M}$ Mueller, ${ }^{3} \mathrm{~T}$ Rau, ${ }^{4} \mathrm{E}$ Epstein, 2J Carlson. 'University Hospital bern, OBGYN, Bern, Switzerland; ${ }^{2}$ Karolinska University Hospital, Department of Oncology-Pathology, Karolinska Institutet, and Department of Pathology and Cytology, Stockholm, Sweden; ${ }^{3}$ Institute of Pathology, University of Bern, Bern, Switzerland; ${ }^{4}$ Karolinska Institutet, Department of Clinical Science and Education and Department of Obstetrics and Gynecology, Södersjukhuset, Stockholm, Sweden, Stockholm, Sweden

\subsection{6/ijgc-2021-ESG0.202}

Introduction/Background* In 2021, a joint ESGO/ESTRO/ESP committee updated their evidence-based guidelines for endometrial cancer, recommending a new risk grouping incorporating both clinicopathologic and molecular parameters. We applied the new risk grouping and compared the results to those of the prior 2016 clinicopathologic system.

Methodology We classified molecularly a cohort of 604 women diagnosed with endometrial cancer using immunohistochemistry for TP53 and MMR proteins on a tissue microarray, as well as Sanger sequencing for POLE mutations. These results, combined with clinicopathologic data, allowed the patients to be risk grouped using both the new 2021 molecular/clinicopathologic parameters and the prior 2016 clinicopathologic system.

Result(s)* The application of the 2021 molecular markers shows Kaplan-Meier curves with a significant difference between the groups for all survival. Molecular classification under the 2021 guidelines revealed a total of 39 patients (39/ $594,7 \%$ ) with a change in risk group in relation to the 2016 classification system: the shift was alone due to either P53abn or POLEmut molecular marker. In order to ensure correct 2021 molecular risk classification, not all patients with endometrial cancer need a molecular diagnostic: 433 (72.9\%) cases 